\title{
The Shielding Ability of Novel Tungsten Rubber Against the Electron Beam for Clinical Use in Radiation Therapy
}

\author{
KENTA KIJIMA $^{1,2}$, HAJIME MONZEN ${ }^{1}$, KENJI MATSUMOTO ${ }^{1}$, \\ MIKOTO TAMURA ${ }^{1}$ and YASUMASA NISHIMURA ${ }^{3}$ \\ ${ }^{1}$ Department of Medical Physics, Graduate School of Medical Science, Kindai University, Osaka, Japan; \\ ${ }^{2}$ Department of Radiology, Otsu City Hospital, Shiga, Japan; \\ ${ }^{3}$ Department of Radiation Oncology, Faculty of Medicine, Kindai University, Osaka, Japan
}

\begin{abstract}
Background/Aim: A newly-introduced tungsten containing rubber (TCR) is a potentially useful shielding material in electron radiotherapy because it is lead-free, containing as much as $90 \%$ fine tungsten powder by weight. This study aimed to investigate the shielding ability of TCR against electron beams. Materials and Methods: Transmission of TCR was measured for energies of 4, 6, 9 and $12 \mathrm{MeV}$. Dose profiles were measured to compare the TCR and lead. The electron backscatter factor (EBF) was also compared. Results: The transmission of equivalent thickness for 4, 6, 9 and $12 \mathrm{MeV}$ with TCR $(0.78 \%, 1.34 \%, 2.16 \%$ and $3.08 \%$, respectively) were lower than that with lead $(0.81 \%, 1.44 \%$, $2.19 \%$ and $3.16 \%$, respectively) $(p<0.05)$. The dose profiles were not significantly different for TCR and lead. The EBF with TCR was up to $17 \%$ lower than that with lead. Conclusion: TCR has adequate radiation shielding ability for electron beams and could be employed instead of lead.
\end{abstract}

In electron radiotherapy, shields are placed on the patient's body surface or attached on the applicator to block beams and scattered rays. In general, the shielding is made from lead or a low-melting point alloy (LMA) and it limits radiation to the appropriate area by shaping the irradiation field. Lead and LMA provide excellent shielding against electron rays and are available at a reasonable price. There has been a number of reports on the dose characteristics of electron beams with lead shields and the dose is considered to depend on the energy, size of the irradiation field and thickness of the shielding

Correspondence to: Hajime Monzen, Ph.D., Department of Medical Physics, Graduate School of Medical Science, Kindai University, 3772, Ohno-Higashi, Osakasayama, Osaka, 859-8511, Japan. Tel: +81 723660221, Fax: +81 723680206, e-mail: hmon@med.kindai.ac.jp

Key Words: Radiation shielding, tungsten containing rubber, electron radiation therapy. material (1-4). However, lead shields are not easy to process, with odors during processing, harmful effects on the environment and possible toxicities for the human body (5). Materials made of high atomic-number elements, such as tungsten, are possible substitutes for lead $(6,7)$, although, they are costly and also difficult to process. Recently, easily processed tungsten functional paper (TFP) was described by Fujimoto et al., Monzen et al., Kamomae et al. and Tamura et al., who investigated its shielding abilities for x-rays, gamma rays and electron beams (8-11).

Tungsten containing rubber (TCR), a novel shielding material, was also recently developed. The aim of this study was to compare the shielding abilities of TCR and lead against electron beams. Their dosimetric characteristics with electron beams and their possible clinical applications were investigated.

\section{Materials and Methods}

Equipment. TCR was prepared by Hayakawa Rubber Co., Ltd. (Hiroshima, Japan) as a sheet-form shielding material, with a length and width of $25 \mathrm{~cm}$, density of $7.65 \pm 0.03 \mathrm{~g} / \mathrm{cm}^{3}$ and thickness and weight combinations of $1 \mathrm{~mm}$ for $0.5 \mathrm{~kg}$ and $2 \mathrm{~mm}$ for $1 \mathrm{~kg}$ (Table I shows other physical properties of TCR). The elemental ratios of TCR (mol\%) were H: $1.0 \%, \mathrm{C}: 6.5 \%$, O: $0.5 \%$ and $\mathrm{W}: 90.0 \%$. Electron beams with nominal energies of $4,6,9$ and $12 \mathrm{MeV}$, generated by Synergy (Elekta, Stockholm, Sweden), were employed. The water-equivalent phantom, Tough Water Phantom (Kyoto Kagaku Co, Ltd., Kyoto, Japan) was used in this study. The following measurements were performed to evaluate the shielding ability of TCR: (1) The transmission for different TCR thicknesses, using a parallel-plate ionization chamber PPC40 (IBA Dosimetry GmbH, Germany); (2) The lateral dose profiles for the size of the irradiation field formed by processed TCR, using a 2D array detector Profiler2 (Sun Nuclear, FL, USA). The same measurements were also performed with a lead shield (Yoshizawa LD Co., Ltd., Osaka, Japan).

First, the equivalent thickness of shielding materials was set based on the maximum distance $\left(R_{\max }\right)$ of each electron energy. 
$R_{\max }$ is the largest penetration depth of electrons in the shielding. Therefore, the equivalent shield thickness was defined as the smallest integer that was larger than $R_{\max }$.

$R_{\max }$ was calculated from the following formula (12):

$(5.42 \times($ energy of the electron beam $)-1.33)$

$R_{\max }(\mathrm{mm})=\frac{}{\text { (density of shielding materials) }}$

Table II shows $R_{\max }$ and equivalent shield thicknesses of TCR and lead under the different electron energies.

Measurement of transmission and electron backscatter factor. The TCR and lead were separately placed on the surface of the waterequivalent phantom. The cone size was $10 \times 10 \mathrm{~cm}^{2}$. The PPC40 was used in all measurements for point doses (13) (Figure 1A). At measurement, the monitor unit (MU) was set to $100 \mathrm{MU}$. First, the open field outputs without any shielding materials were measured at three reference points, which were at surface, $0.5 \mathrm{~cm}$ and $1.5 \mathrm{~cm}$ depths in the water-equivalent phantom. Second, the transmission of TCR with thicknesses of 1 to $12 \mathrm{~mm}$ was measured for electron energies of 4, 6, 9 and $12 \mathrm{MeV}$. Each transmission of the respective thickness was normalized by the open field output. In addition, transmission with TCR of equivalent thickness was also measured at a depth of the dose maximum $\left(d_{\max }\right)$ for each energy. The $d_{\max }$ values were $9 \mathrm{~mm}$ for $4 \mathrm{MeV}, 13 \mathrm{~mm}$ for $6 \mathrm{MeV}, 21 \mathrm{~mm}$ for $9 \mathrm{MeV}$ and $28 \mathrm{~mm}$ for $12 \mathrm{MeV}$. Hence, the equivalent thicknesses of TCR and lead were 3 and $2 \mathrm{~mm}$, respectively, for $4 \mathrm{MeV}, 5$ and $3 \mathrm{~mm}$ for $6 \mathrm{MeV}, 7$ and $5 \mathrm{~mm}$ for $9 \mathrm{MeV}$ and 9 and $6 \mathrm{~mm}$ for $12 \mathrm{MeV}$. Finally, the electron backscatter factors (EBFs) for the equivalent thickness shielding materials were measured at depths ranging from 0 to $20 \mathrm{~cm}$ in the water-equivalent phantom, using PPC40 (Figure 1B). The electron backscatter contributes to producing significantly high dose enhancements near the tissue-shield interface. The enhancement in dose at the tissue-metal interface is dependent on the beam energy at the interface and the atomic number of the metal (13). The EBF was estimated by the following equation:

(ionization amount with the equivalent shield thickness of TCR or lead at each depth)

$\mathrm{EBF}=$

(ionization amount with the equivalent shield thickness of lead at $0 \mathrm{~cm}$ depth)

Measurement of the dose profile. The geometry of the measurement of the dose profile is shown in Figure 1C. TCR was placed on the 2D array detector without any buildup materials (14). The TCR thicknesses were 3, 5, 7 and $9 \mathrm{~mm}$ for $4,6,9$ and $12 \mathrm{MeV}$, respectively. The lateral dose profile was measured to evaluate the irradiation field size, the flatness and the penumbra trimmed by TCR. The evaluated irradiation field size was defined at the 50\% dose level, which was normalized at the center. The flatness was calculated as the ratio of the maximum dose to the dose at the center of the field. The penumbra was determined as the distance between the $80 \%$ and the $20 \%$ dose points along the $x$-axis (13). The cone size was $10 \times 10 \mathrm{~cm}^{2}$ and $3 \mathrm{~cm}$ in the positive direction of the $\mathrm{x}$-axis was shielded. Therefore, the field negative direction of the $x$-axis was $5 \mathrm{~cm}$ and the positive direction of the $\mathrm{x}$-axis was $2 \mathrm{~cm}$ opened, as shown in Figure 1C. For comparison, the lateral dose profile
Table I. Physical properties of TCR.

\begin{tabular}{lc}
\hline Item & Value \\
\hline Hardness (Type-A) & 77 \\
Tensile strength (MPa) & 4.5 \\
Elongation (\%) & 400 \\
\hline
\end{tabular}

Table II. $R_{\max }$ and equivalent shield thickness of TCR and lead.

\begin{tabular}{lccccc}
\hline $\begin{array}{l}\text { Electron Energy } \\
(\mathrm{MeV})\end{array}$ & \multicolumn{2}{c}{$\begin{array}{c}\mathrm{R}_{\max } \\
(\mathrm{mm})\end{array}$} & & \multicolumn{2}{c}{$\begin{array}{c}\text { Equivalent shield } \\
\text { thickness }(\mathrm{mm})\end{array}$} \\
\cline { 2 - 3 } \cline { 5 - 7 } & $\mathrm{TCR}$ & Lead & & TCR & Lead \\
\hline 4 & 2.678 & 1.795 & & 3 & 2 \\
6 & 4.104 & 2.750 & & 5 & 3 \\
9 & 6.243 & 4.184 & & 7 & 5 \\
12 & 8.383 & 5.618 & & 9 & 6 \\
\hline
\end{tabular}

Shield densities of TCR and lead were 7.6 and 11.34, respectively.

shielded by lead was measured under the same conditions. The thickness of the lead plate was based on information in Table II and the size of the irradiation field was also $2 \mathrm{~cm}$.

\section{Results}

Measurement of transmission and electron backscatter factor. The result of measurements of TCR thickness and transmission for $10 \times 10 \mathrm{~cm}^{2}$ field sizes at 4, 6, 9 and $12 \mathrm{MeV}$ electron energies are shown in Figure 2 and Table III. The transmission was decreased exponentially, as the thickness of TCR was increased. At $4 \mathrm{MeV}, 95 \%$ dose reduction was obtained with $2 \mathrm{~mm}$ TCR thickness. A 95\% dose reduction was also obtained at $3 \mathrm{~mm}$ TCR thickness for $6 \mathrm{MeV}, 5 \mathrm{~mm}$ for $9 \mathrm{MeV}$ and $9 \mathrm{~mm}$ for $12 \mathrm{MeV}$. In addition, about a $20 \%$ dose increase because of build-up was observed with a shield thickness of $1 \mathrm{~mm}$ at electron energies of 9 and $12 \mathrm{MeV}$. The equivalent thickness of TCR was $3 \mathrm{~mm}$ for $4 \mathrm{MeV}, 5 \mathrm{~mm}$ for $6 \mathrm{MeV}, 7 \mathrm{~mm}$ for $9 \mathrm{MeV}$ and $9 \mathrm{~mm}$ for $12 \mathrm{MeV}$. The equivalent thicknesses of TCR for each electron energy corresponded with most of the measurement results.

The transmission of $6 \mathrm{MeV}$ for TCR thicknesses between 0 to $12 \mathrm{~mm}$ at measurement depths of surface, $0.5 \mathrm{~cm}$ and 1.5 $\mathrm{cm}$ is shown in Figure 3. The transmission was decreased exponentially as the thickness of TCR increased. The transmission of the equivalent shield thickness $(5 \mathrm{~mm})$ and the measured maximum shield thickness $(12 \mathrm{~mm})$ was $1.8 \%$ and $1.2 \%$ at surface, $1.6 \%$ and $1.0 \%$ at $0.5 \mathrm{~cm}$, and $1.3 \%$ and $0.9 \%$ at $1.5 \mathrm{~cm}$, which indicated that the differences were small. In addition, the increment of the surface dose was confirmed to be $1 \mathrm{~mm}$ TCR thickness, as shown in Figure 3. The results of transmission between TCR and lead with the equivalent shield 


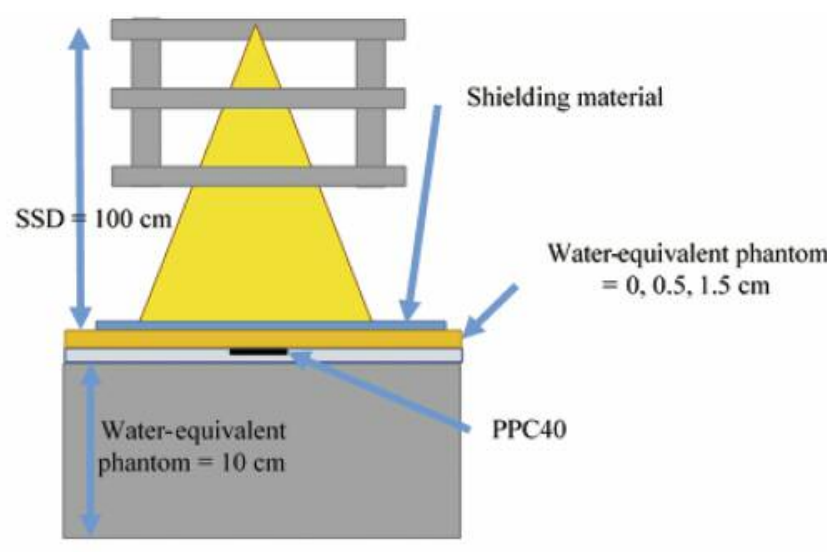

A) Transmission measurement

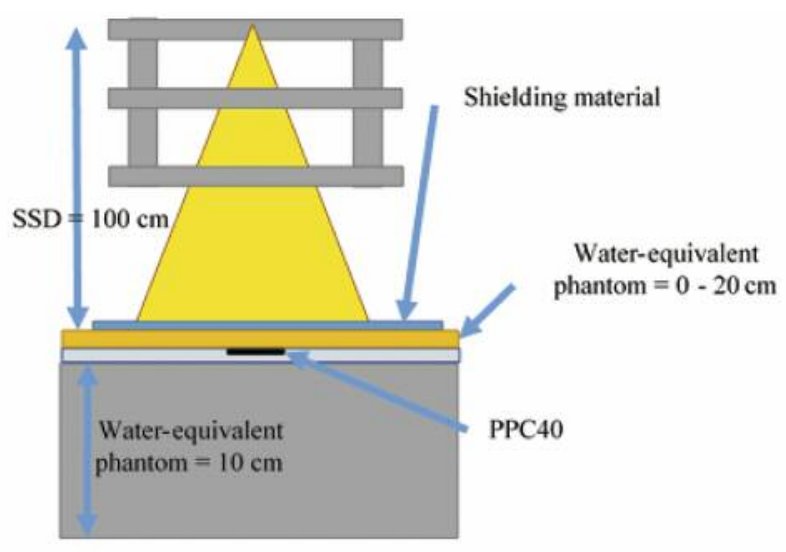

B) EBF measurement

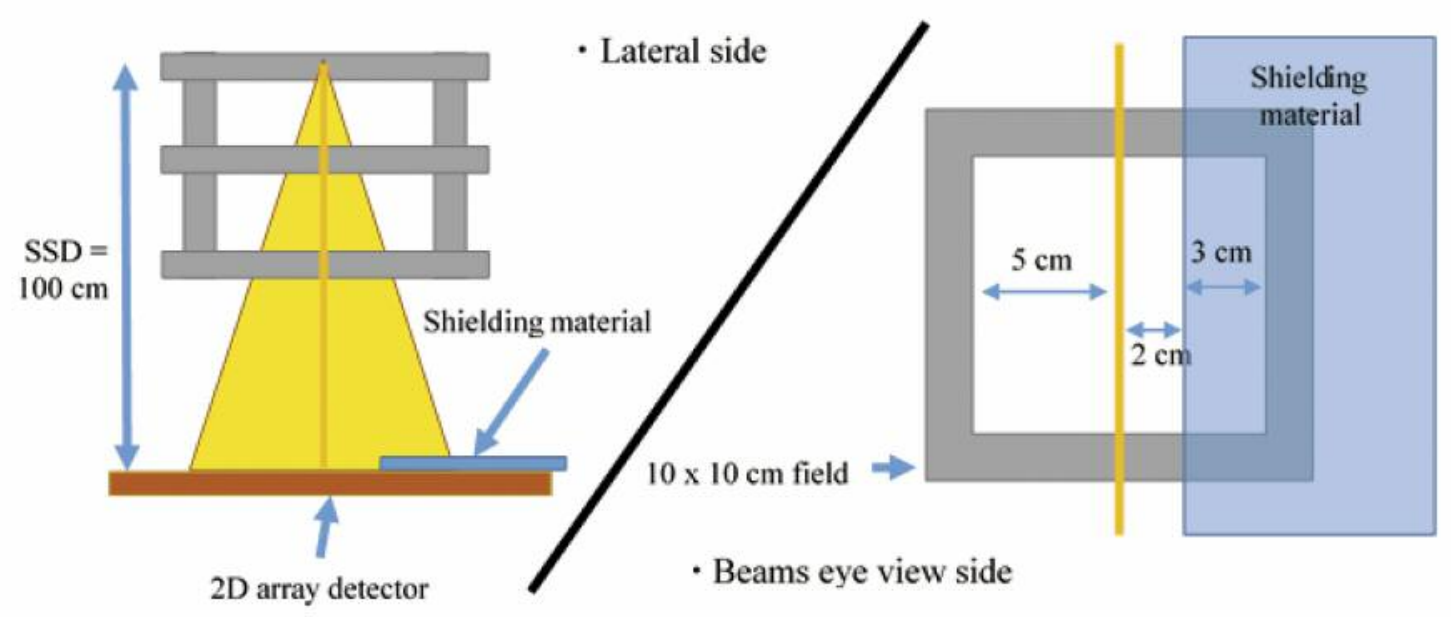

\section{C) Dose profile measurement}

Figure 1. Schematic diagram of the experimental set-up. A: Transmission measurement for a $10 \times 10 \mathrm{~cm}^{2}$ field size with TCR of different thicknesses $(0.0,1.0,2.0,3.0,5.0,7.0,9.0,11.0$ and $12.0 \mathrm{~mm})$ at surface $(=0 \mathrm{~cm}), 0.5 \mathrm{~cm}$ and $1.5 \mathrm{~cm}$ depths. B: EBF measurements for a $10 \times 10 \mathrm{~cm}{ }^{2}$ field size with equivalent thickness shields at 0 to $20 \mathrm{~cm}$ depths. C: Dose profile measurements for a $10 \times 7 \mathrm{~cm}^{2}$ field size with equivalent thickness shields.

thickness measured at $d_{\max }$ and with electron energies of 4 to $12 \mathrm{MeV}$ are shown in Figure 4. With all electron energies from 4 to $12 \mathrm{MeV}$, the transmission of TCR was lower than that of lead and was lower by $0.1 \%$ at the maximum $(p<0.05)$.

A comparison of EBF between TCR and lead at the corresponding equivalent shield thicknesses with electron energies of 4-12 MeV is shown in Figure 5. Each EBF was normalized by the respective measurement value of lead at a 0 $\mathrm{cm}$ depth. EBF with both TCR and lead decreased exponentially as the measurement depth increased. At all depths, the EBF of TCR was lower than that of lead, as well as at all electron energies. At a $0 \mathrm{~cm}$ depth and $4 \mathrm{MeV}$ electron energy, the EBF of TCR was reduced by up to $17 \%$ compared with that of lead. The results of transmission for a $10 \times 10 \mathrm{~cm}^{2}$ field size with 1 mm TCR thickness at electron energies of 4, 6, 9 and $12 \mathrm{MeV}$ are shown in Figure 6. Each transmission curve was normalized by the measurement value without TCR for $d_{\max }$ corresponding to each electron energy. With electron energies of 4 and $6 \mathrm{MeV}$, as measurement depth was greater, the transmission with $1 \mathrm{~mm}$ TCR thickness was decreased exponentially. With electron energies of 9 and $12 \mathrm{MeV}$, as measurement depth increased, the transmission with 1-mm TCR thickness showed a shouldering 


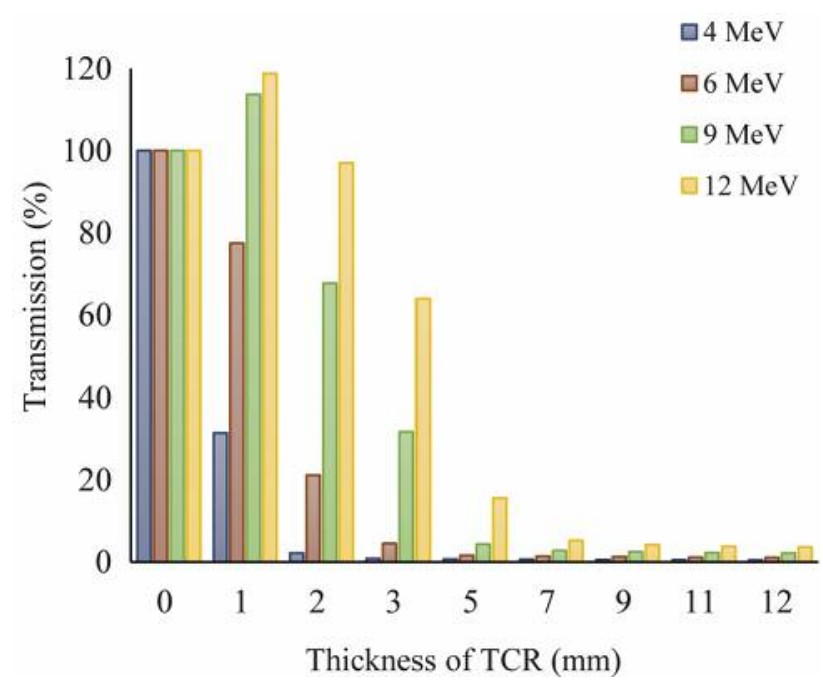

Figure 2. Relationship between TCR thickness and transmission for a $10 \times 10 \mathrm{~cm}^{2}$ field size at 4, 6, 9 and $12 \mathrm{MeV}$ electron energies. The horizontal axis shows the TCR thickness and the vertical axis shows the transmission measured at the $0.5 \mathrm{~cm}$ buildup in the water-equivalent phantom. The transmission bars were normalized to measurement values without TCR for the respective electron beam energies.

Table III. Transmission values of TCR (\%) for 4, 6, 9 and $12 \mathrm{MeV}$ electron energies.

\begin{tabular}{lrrrrrrrrrr}
\hline $\begin{array}{l}\text { Electron Energy } \\
\text { (MeV) }\end{array}$ & \multicolumn{10}{c}{ Thickness of TCR (mm) } \\
\cline { 2 - 9 } & \multicolumn{1}{c}{0} & 1 & 2 & 3 & 5 & 7 & 9 & 11 & 12 \\
\hline 4 & 100.0 & 31.4 & 2.2 & 0.8 & 0.7 & 0.6 & 0.6 & 0.5 & 0.5 \\
6 & 100.0 & 77.4 & 21.1 & 4.5 & 1.6 & 1.4 & 1.3 & 1.1 & 1.0 \\
9 & 100.0 & 113.7 & 67.7 & 31.7 & 4.3 & 2.8 & 2.5 & 2.3 & 2.1 \\
12 & 100.0 & 118.8 & 97.0 & 63.9 & 15.5 & 5.2 & 4.2 & 3.8 & 3.6 \\
\hline
\end{tabular}

The transmission was measured at the $0.5-\mathrm{cm}$ buildup in the waterequivalent phantom.

exponential decline. As electron energy increased, the dose increment was $0 \mathrm{~cm}$. The results of the transmission at $0 \mathrm{~cm}$ were: $57.98 \%$ for $4 \mathrm{MeV}, 99.13 \%$ for $6 \mathrm{MeV}, 120.84 \%$ for 9 $\mathrm{MeV}$ and $121.59 \%$ for $12 \mathrm{MeV}$.

Measurement of dose profile. The lateral dose profiles with TCR and lead at 4, 6, 9 and $12 \mathrm{MeV}$ electron energies are shown in Figure 7. As the energy of the electron beam increased, the dose of the periphery of the shield edge was increased for both TCR and lead. Table IV shows the results of the covered side of the field size, flatness and penumbra of TCR and lead for each electron energy. The results of the

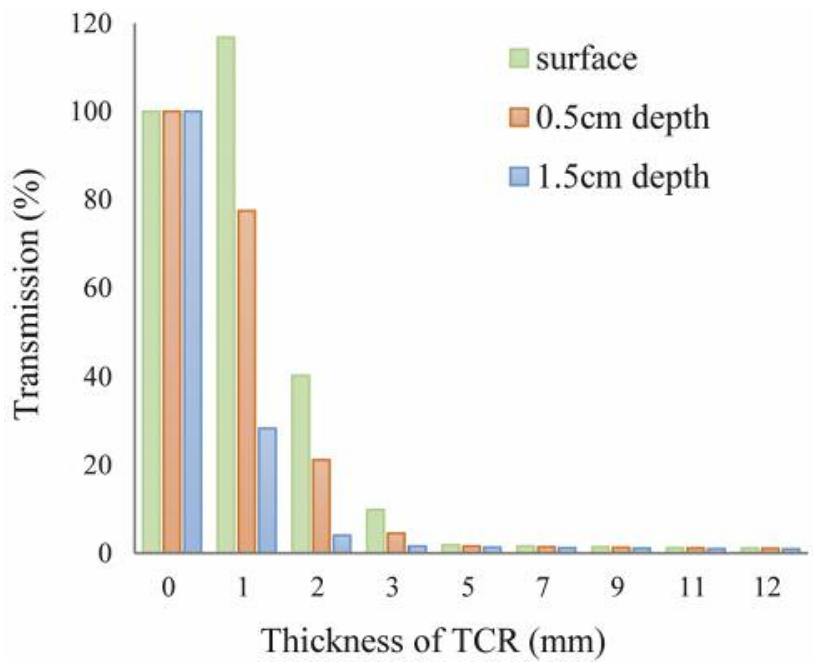

Figure 3. Relationship between TCR thickness and transmission for a $10 \times 10 \mathrm{~cm}^{2}$ field size at an electron energy of $6 \mathrm{MeV}$. The horizontal axis shows the TCR thickness and the vertical axis shows the transmission that was measured at the surface, $0.5 \mathrm{~cm}$ and $1.5 \mathrm{~cm}$, in the water-equivalent phantom. The transmission bars were normalized by the measurement value without TCR for each measured depth.

covered side of the field size of TCR and lead under the respective energies were 2.08 and $2.04 \mathrm{~cm}$ for $4 \mathrm{MeV}, 2.09$ and $2.08 \mathrm{~cm}$ for $6 \mathrm{MeV}, 2.09$ and $2.12 \mathrm{~cm}$ for $9 \mathrm{MeV}, 2.13$ and $2.10 \mathrm{~cm}$ for $12 \mathrm{MeV}$. The results of the covered side of the flatness of TCR and lead under the respective energies were $100.29 \%$ and $100.23 \%$ for $4 \mathrm{MeV}, 100.59 \%$ and $100.54 \%$ for $6 \mathrm{MeV}, 102.42 \%$ and $102.19 \%$ for $9 \mathrm{MeV}, 102.53 \%$ and $103.59 \%$ for $12 \mathrm{MeV}$. The results of the covered side of the penumbra of TCR and lead were 0.68 and $0.69 \mathrm{~cm}$ for $4 \mathrm{MeV}$, 0.60 and $0.60 \mathrm{~cm}$ for $6 \mathrm{MeV}, 0.53$ and $0.51 \mathrm{~cm}$ for $9 \mathrm{MeV}$ and 0.49 and $0.52 \mathrm{~cm}$ for $12 \mathrm{MeV}$. These results showed that the dose profiles were not significantly different for TCR and lead.

\section{Discussion}

In this study, the shielding abilities of TCR and lead were compared to clarify the dosimetric characteristics of TCR for electron beams and, therefore, its potential use in clinical applications.

Transmission was decreased with increased TCR thickness. However, increased transmission was observed when TCR thickness was $1 \mathrm{~mm}$ for electron beams of greater than 9 $\mathrm{MeV}$, because buildup occurred at a depth of $0.5 \mathrm{~cm}$. These findings correlated well with previous studies. For the equivalent TCR shield thickness, transmission was attenuated more than 95\% for each energy, as shown in Figure 2. This was enough to shield the electron beams in a manner similar 


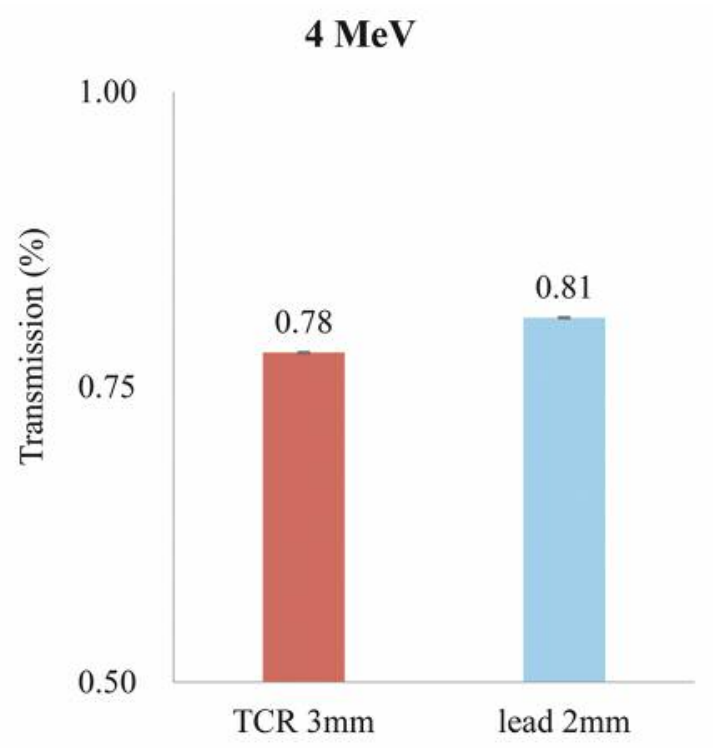

Shielding material and thickness $(\mathrm{mm})$

\section{$9 \mathrm{MeV}$}

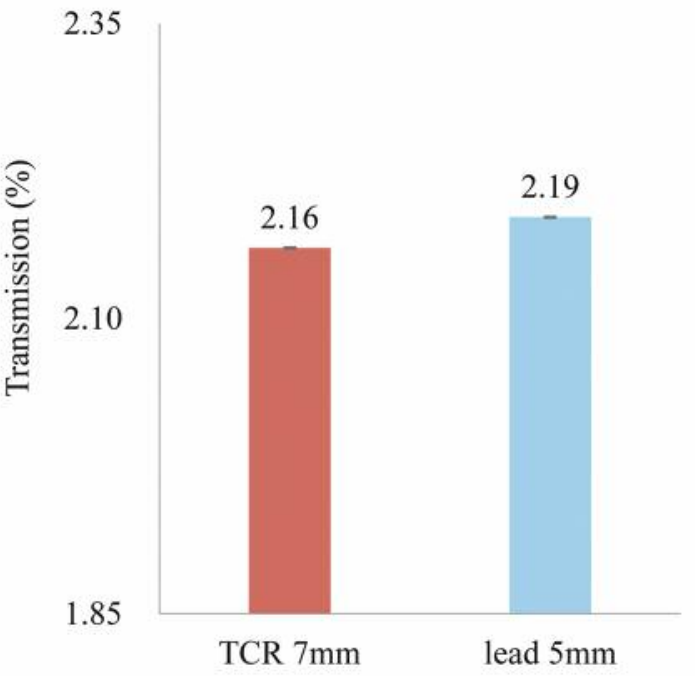

Shielding material and thickness $(\mathrm{mm})$

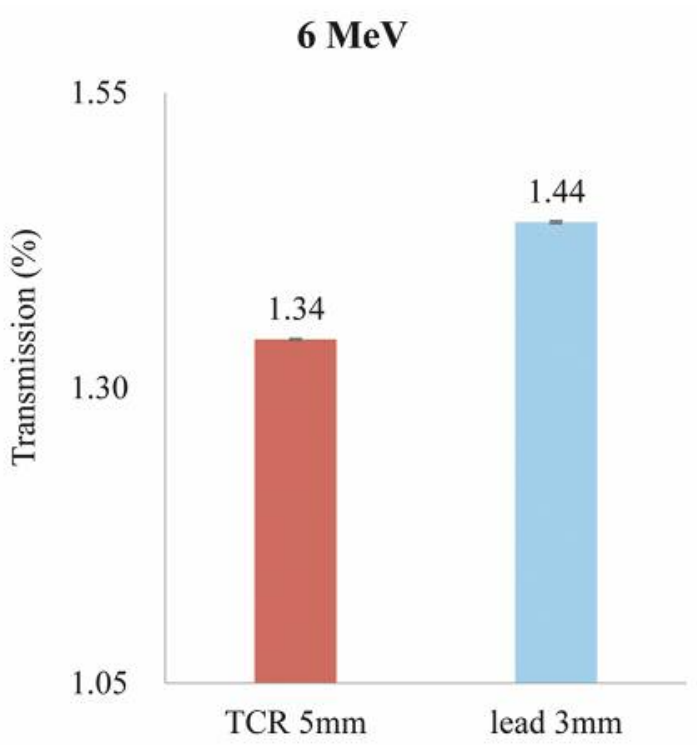

Shielding material and thickness $(\mathrm{mm})$

\section{$12 \mathrm{MeV}$}

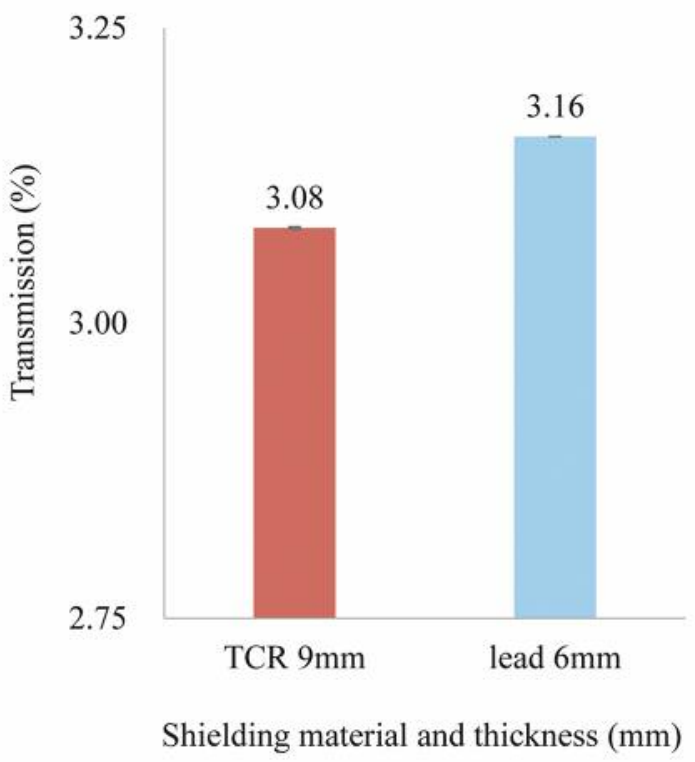

Figure 4. Comparison of transmission of TCR and lead at $d_{\text {max }}$ with equivalent thicknesses for 4, 6, 9 and 12 MeV electron energies. The horizontal axis shows the shield thickness and the vertical axis shows the transmission.

Table IV. Field size, flatness, and penumbra for covered side with none, TCR, and lead.

\begin{tabular}{|c|c|c|c|c|c|c|c|c|c|}
\hline \multirow[t]{2}{*}{ Electron Energy (MeV) } & \multicolumn{3}{|c|}{ Field size $(\mathrm{cm})$} & \multicolumn{3}{|c|}{ Flatness (\%) } & \multicolumn{3}{|c|}{ Penumbra $(\mathrm{cm})$} \\
\hline & none & TCR & lead & none & TCR & lead & none & TCR & lead \\
\hline 4 & 5.24 & 2.08 & 2.04 & 100.00 & 100.29 & 100.23 & 1.30 & 0.68 & 0.69 \\
\hline 6 & 5.23 & 2.09 & 2.08 & 100.00 & 100.59 & 100.54 & 1.08 & 0.60 & 0.60 \\
\hline 9 & 5.25 & 2.09 & 2.12 & 100.00 & 102.42 & 102.19 & 0.77 & 0.53 & 0.51 \\
\hline 12 & 5.24 & 2.13 & 2.10 & 100.00 & 102.53 & 103.59 & 0.67 & 0.49 & 0.52 \\
\hline
\end{tabular}



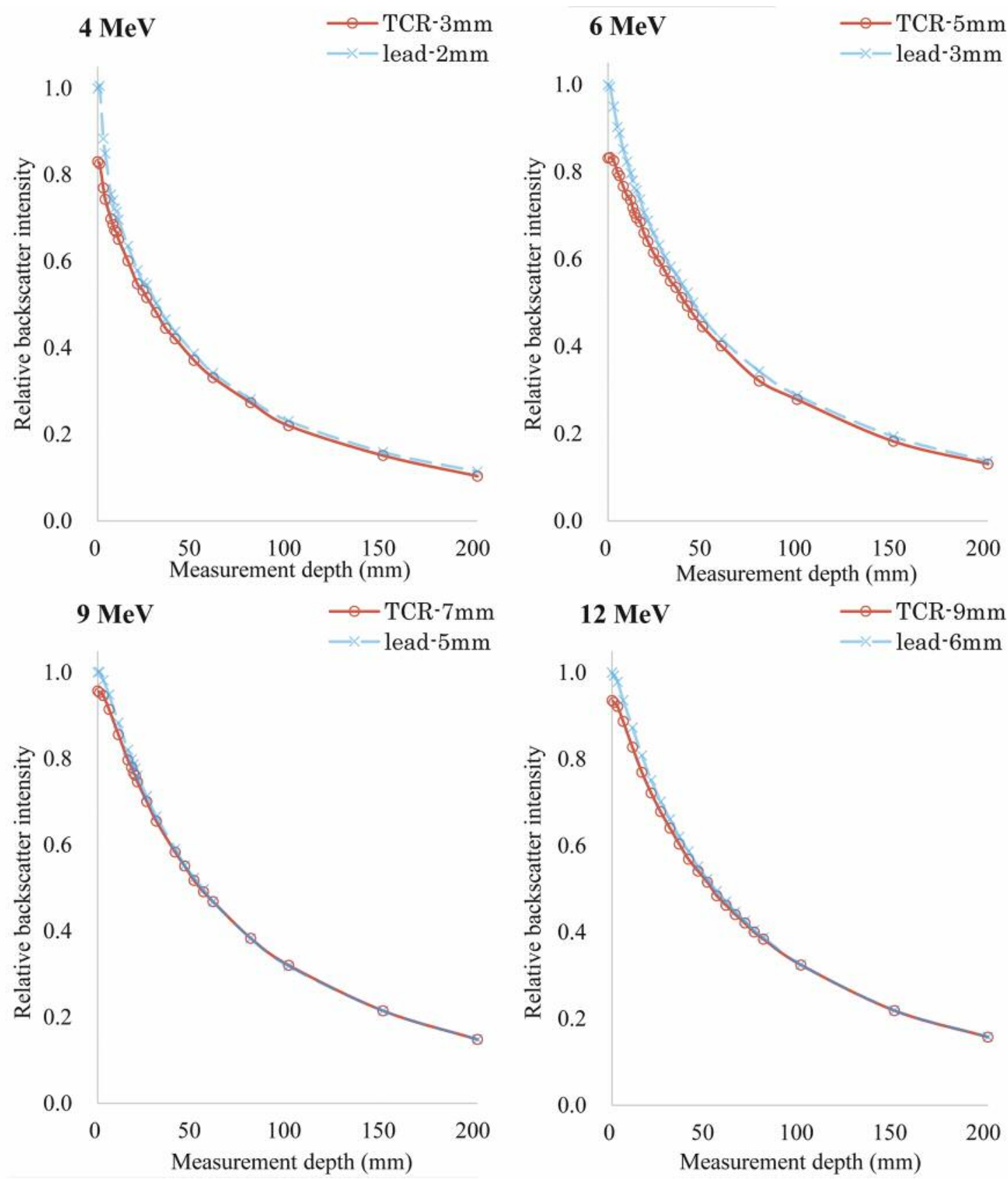

Figure 5. Comparison of EBF for TCR and lead at 4, 6, 9 and $12 \mathrm{MeV}$ electron energies. The horizontal axis shows the measurement depth and the vertical axis shows the relative backscatter intensity measured at the indicated depth in the water-equivalent phantom. The shield thickness is the equivalent thickness. The relative backscatter intensity curves were normalized to the measurement values of lead at a $0 \mathrm{~cm}$ depth.

to shielding by lead (Figure 4). In electron-beam therapy of up to $12 \mathrm{MeV}$, TCR with a $9 \mathrm{~mm}$ thickness could be used sufficiently at clinical sites without any shielding concerns. In addition, the equivalent shield thickness calculated from $R_{\max }$ was confirmed to be a useful index for calculating the equivalent TCR thickness for a clinical site.
Fujimoto et al. showed that the irradiation field size was nearly equal for TFP and lead. However, the lateral dose profile of the irradiation field shaped with TFP gradually increased in dose toward the periphery of the irradiation field. Our results agreed well with this report. As with TFP, TCR and lead had similar dose characteristics against 

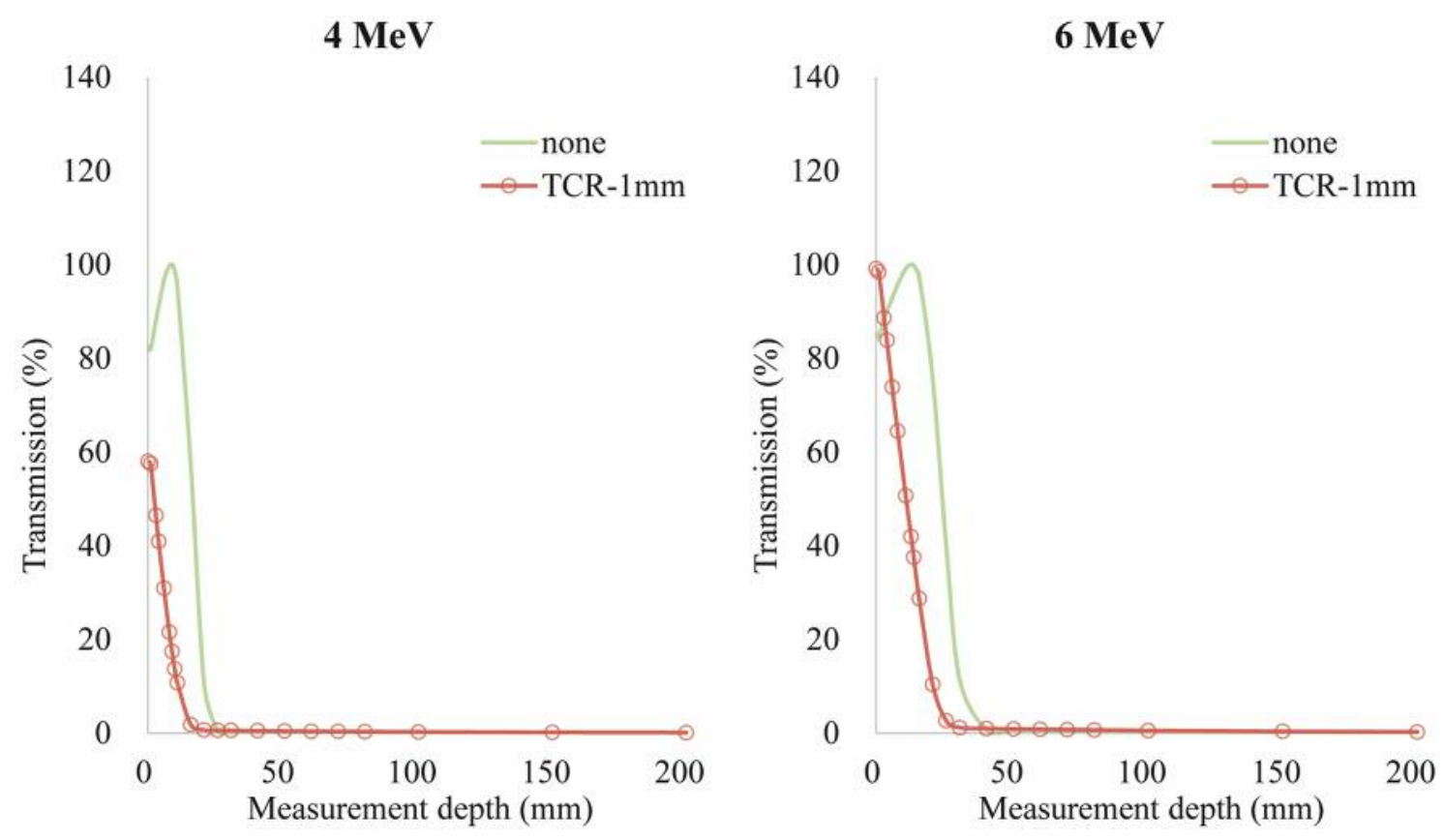

\section{$9 \mathrm{MeV}$}
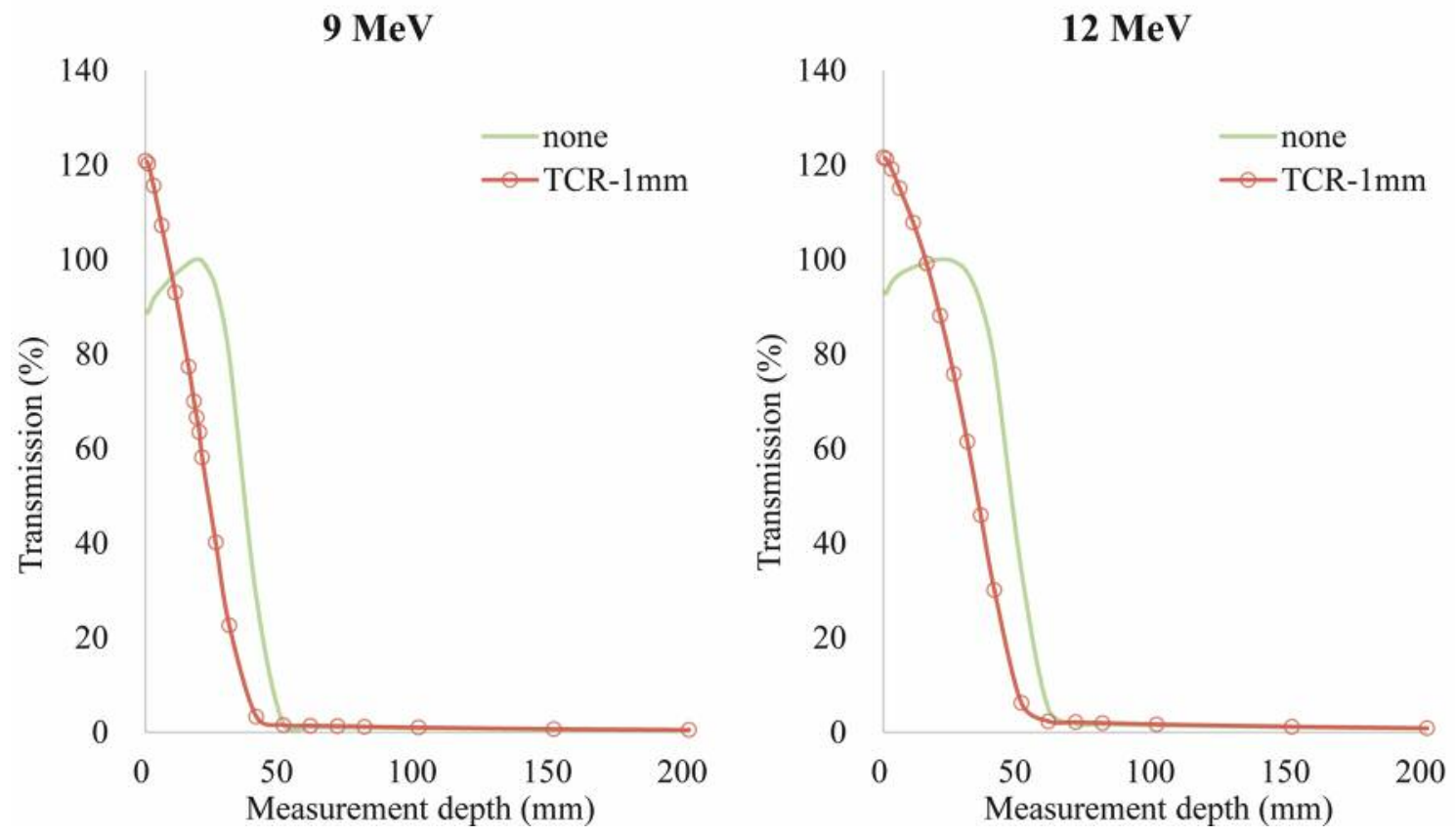

Figure 6. Relationship between measurement depth and transmission for a $10 \times 10 \mathrm{~cm}^{2}$ field size with a $1 \mathrm{~mm}$ TCR thickness at electron energies of 4, 6, 9 and $12 \mathrm{MeV}$. The horizontal axis shows the measurement depth and the vertical axis shows the transmission that was measured in the waterequivalent phantom. The transmission curves were normalized to the measurement values without TCR for $d_{\text {max }}$ corresponding to each electron energy.

electron beams (8). In the lateral dose profiles, the irradiation field size, flatness and penumbra for TCR were nearly equal to those for lead. The difference between the peripheral and the central dose was the largest at an electron energy of 12 $\mathrm{MeV}, 2.5 \%$ for TCR and $3.6 \%$ for lead. The increase in peripheral dose was caused by scattered rays from the shielding material and depended primarily on shield thickness.

TFP and a hydrogenated styrene-butadiene-styrene copolymer (SEBS) described by Yue et al. were also studied 

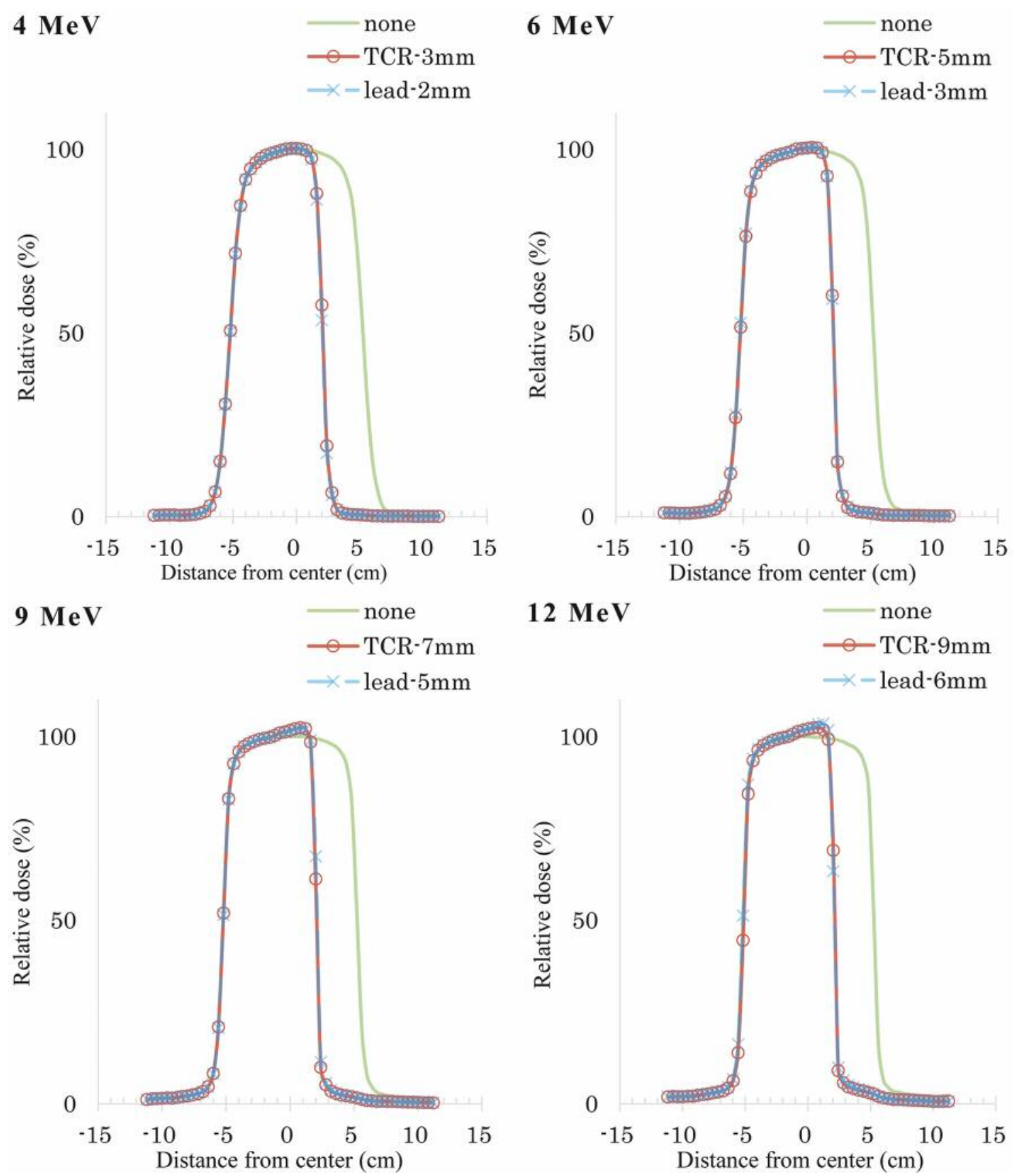

Figure 7. Comparison of dose profiles for TCR and lead at 4, 6, 9 and $12 \mathrm{MeV}$ electron energies. The horizontal axis shows the x-axis of the irradiated field $\left(7 \times 10 \mathrm{~cm}^{2}\right)$ and the vertical axis shows the relative dose normalized at the isocenter position.

as new shielding materials for electron radiotherapy $(6,8$, 11). TCR has useful characteristics similar to those of TFP and SEBS. First, TCR is softer and easier to process than lead. TCR is expected to shape irradiation fields that are equivalent to or even more complicated than those shaped by other materials. Conventional electron radiotherapy was performed with the tubus, collimator or shield made from lead or LMA. The irradiation field of the tubus was limited to a predetermined aperture size and a collimator and shield made from lead or LMA required a long time to shape the irradiation field. However, TCR can shape an irradiation field more flexibly and quickly than these other materials. 
Second, TCR can also be used for grid therapy, instead of TFP (11). It is possible to restore the penumbra when treating at extended SSD by placing collimation on the skin surface (13). When placed on patients, TCR can suppress their movement. In addition, TCR is soft enough to be placed on a curved part of a patient's body, such as the face, ear, shoulder or belly. Meanwhile in the clinic, the bremsstrahlung caused by interactions between the electron beam and the shield, and the bolus effects of the shield itself are potential problems $(8,11,15)$. Generally, bremsstrahlung is proportional to the electron energy and the atomic number of the shielding material. Tungsten may reduce bremsstrahlung, compared with lead, because of its lower atomic number. If the shielding materials are placed directly on the patient's skin surface, a bolus effect could result (8). However, the bolus effect from TCR was smaller than that from lead. As Figure 5 shows, TCR could reduce the skin surface dose up to $17 \%$, compared with lead, when placed directly on the patient's skin surface. One reason for this might be because TCR is a mixture of high and low density materials (16). Conversely, the bolus effect caused by $1 \mathrm{~mm}$ thick TCR, as shown in Figure 7, suggested that it has advantages for radiation therapy on the skin surface, such as in treating angiosarcoma.

TCR can readily shape the irradiation field and is less harmful to the human body than LMA, which releases toxic substances during processing, although at levels lower than the reference (5). While the cost of TCR is slightly higher than that of lead of the same size, the price may be reduced by recycling or re-manufacturing after use and, in addition, we are developing a non-disposable clay-like TCR. This could make it possible to use limited resources effectively in the future.

\section{Conclusion}

TCR is a novel and flexible shielding material containing a metal with a high atomic number in rubber and it has a shielding ability that is equivalent to or higher than that of lead. TCR has adequate radiation shielding ability for electrons within the energy range used in radiotherapy and could, therefore, be employed instead of lead at clinical sites.

\section{Conflicts of Interest}

Hajime Monzen received a research donation from Hayakawa rubber Co., LTD.

\section{Acknowledgements}

This work was supported partly by JSPS KAKENHI grant numbers 16K09027 and 17K09071. The Authors thank Susan R. Doctrow, $\mathrm{PhD}$, from Edanz Group (www.edanzediting.com/ac) for editing a draft of this manuscript.

\section{References}

1 Khan FM, Werner BL and Deibel FC: Lead shielding for electrons. Med Phys 8: 712-713, 1981.

2 Prasad SG, Parthasaradhi K, Arbetter S, Lee Y and Garces R: Lead shielding thickness for dose reduction of $6-\mathrm{MeV}$ electrons for different square fields. Med Phys 15: 263-266, 1988.

3 Prasad SG, Parthasaradhi K, Lee Y and Garces R: Lead shielding thickness for dose reduction of $5 \mathrm{MeV}$ electrons. Med Phys 16: 807-808, 1989.

4 Giarratano JC, Duerkes RJ and Almond PR: Lead shielding thickness for dose reduction of 7- to $28-\mathrm{MeV}$ electrons. Med Phys 2: 336-337, 1975.

5 Rapisarda V, Ledda C, Castaing M, Proietti L and Ferrante M: Potential exposure to carcinogens in low-melting alloys processing. G Ital Med Lav Ergon 35: 73-76, 2013.

6 Yue K, Luo W, Dong X, Wang C, Wu G, Jiang M and Zha Y: A new lead-free radiation shielding material for radiotherapy. Radiat Prot Dosimetry 133: 256-260, 2009.

7 Tajiri M, Sunaoka M, Fukumura A and Endo M: A new radiation shielding block material for radiation therapy. Med Phys 31: 3022-3023, 2004.

8 Fujimoto T, Monzen H, Nakata M, Okada T, Yano S, Takakura T, Kuwahara J, Sasaki M, Higashimura $\mathrm{K}$ and Hiraoka M: Dosimetric shield evaluation with tungsten sheet in 4, 6, and $9 \mathrm{MeV}$ electron beams. Phys Medica 30: 838-842, 2014.

9 Monzen H, Kanno I, Fujimoto T and Hiraoka M: Estimation of the shielding ability of a tungsten functional paper for diagnostic $\mathrm{x}$ rays and gamma rays. J Appl Clin Med Phys 18: 325-329, 2017.

10 Kamomae T, Monzen H, Kawamura M, Okudaira K, Nakaya T, Mukoyama T, Miyake Y, Ishihara Y, Itoh Y and Naganawa S: Dosimetric feasibility of using tungsten-based functional paper for flexible chest wall protectors in intraoperative electron radiotherapy for breast cancer. Phys Med Biol 63: 15006, 2017.

11 Tamura M, Monzen H, Kubo K, Hirata M and Nishimura Y: Feasibility of tungsten functional paper in electron grid therapy: a Monte Carlo study. Phys Med Biol 62: 878-889, 2017.

12 Podgorsak EB: Radiation Oncology Physics: A Handbook for Teachers and Students. (Podgorsak EB (ed.)). Vienna, International Atomic Energy Agency, 2005.

13 Khan FM, Doppke KP, Hogstrom KR, Kutcher GJ, Nath R, Prasad SC, Purdy JA, Rozenfeld M and Werner BL: Clinical electron-beam dosimetry: Report of AAPM Radiation Therapy Committee Task Group No. 25. Med Phys 18: 73-109, 2003.

14 Praveen Kumar PP, Manisha Singh M and Kumar Mishra P: Analytical Study of Flatness and Symmetry of Electron Beam with 2D Array Detectors. J Cancer Sci Ther 7: 294-301, 2015.

15 Shiomoto A, Akazawa H, Okada T, Yano S, Oya N, Ogawa K, Komatsu R, Morimoto $\mathrm{M}$ and Takakura $\mathrm{T}$ : Evaluation of radiation therapy for keloid using electron beam. Nihon Hoshasen Gijutsu Gakkai Zasshi 60: 429-436, 2004.

16 Weaver RD, Gerbi BJ and Dusenbery KE: Evaluation of eye shields made of tungsten and aluminum in high-energy electron beams. Int J Radiat Oncol Biol Phys 41: 233-237, 1998.

Received April 20, 2018

Revised May 21, 2018

Accepted May 23, 2018 